\title{
Fuzzy Logic For Beginners
}


This page is intentionally left blank 

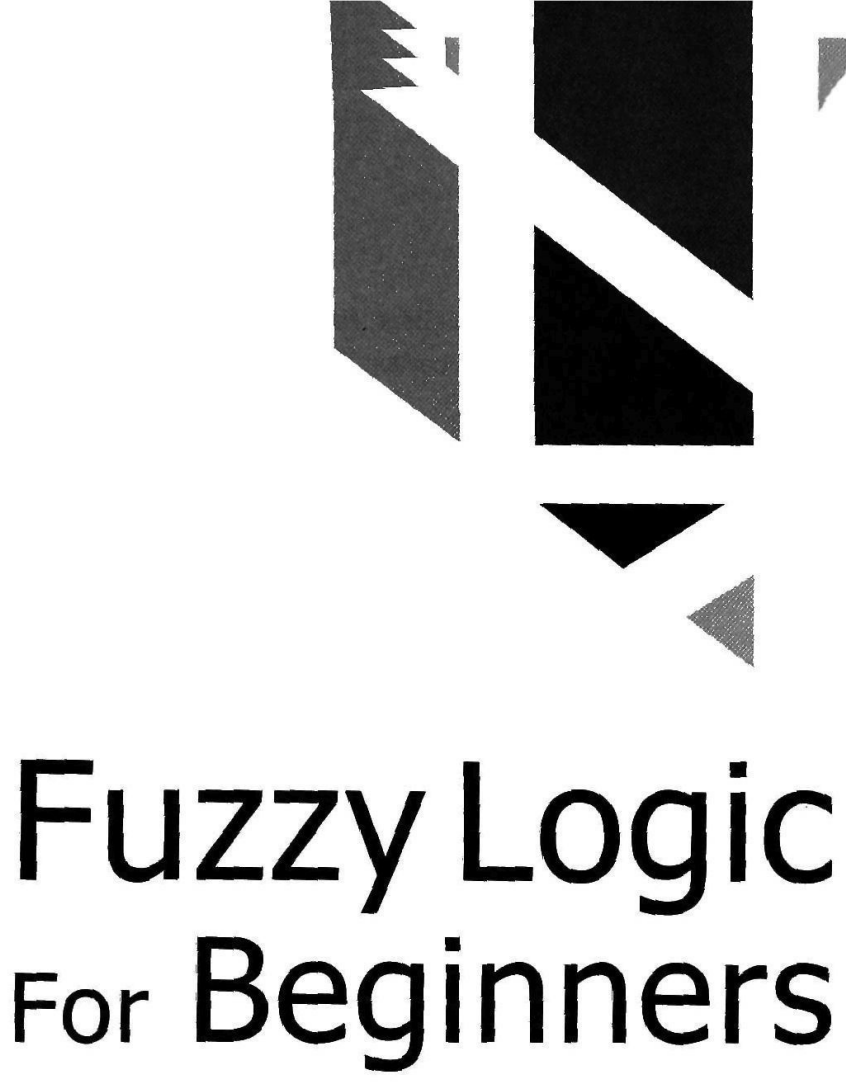

Masao Mukaidono

Meiji University, Japan 
Published by

World Scientific Publishing Co. Pte. Ltd.

5 Toh Tuck Link, Singapore 596224

USA office: Suite 202, 1060 Main Street, River Edge, NJ 07661

UK office: 57 Shelton Street, Covent Garden, London WC2H 9HE

\section{British Library Cataloguing-in-Publication Data}

A catalogue record for this book is available from the British Library.

First published in 2001

Reprinted in 2002, 2004

\section{FUZZY LOGIC FOR BEGINNERS}

Copyright $\odot 2001$ by World Scientific Publishing Co. Pte. Ltd.

All rights reserved. This book, or parts thereof, may not be reproduced in any form or by any means, electronic or mechanical, including photocopying, recording or any information storage and retrieval system now known or to be invented, without written permission from the Publisher.

For photocopying of material in this volume, please pay a copying fee through the Copyright Clearance Center, Inc., 222 Rosewood Drive, Danvers, MA 01923, USA. In this case permission to photocopy is not required from the publisher.

ISBN 981-02-4534-3 


\section{Contents}

1 Considering Fuzziness 1

1.1 Is "Fuzziness" a Vice? . . . . . . . . . . . . . . . . . . . . . 1

1.2 Human-Beings Originally Ambiguous . . . . . . . . . . . 4

1.3 Digital versus Analog . . . . . . . . . . . . . . 4

1.4 Logic for Computer . . . . . . . . . . . . . . 6

1.5 Human Beings Forced to Think Suitably for Computer . . . 7 .

1.6 Contemporary Rationalism Due to Descartes . . . . . . . . 8

1.7 Modern Rationalism at a Deadlock . . . . . . . . . . . . . 9

1.8 Information and Ambiguity . . . . . . . . . . 10

1.9 Requirement of Ambiguity . . . . . . . . . . . . . . . . 11

1.10 Aspect of Ambiguity . . . . . . . . . . . . . . . . . 12

1.11149 Terminologies Concerning Fuzziness . . . . . . . . . . 13

1.12 What is Fuzzy Theory? . . . . . . . . . . . . . . 14

2 Before the Invention of Fuzzy Theory 17

2.1 Invention of Fuzzy Theory - Proposed by Prof. Zadeh in $1965 \ldots \ldots \ldots \ldots \ldots \ldots$. . . . . . . . . . . . . . . .

2.2 Invention of Fuzzy Theory - Limitation of Rigorous Computer Modeling . . . . . . . . . . . . 18

2.3 Fuzzy Theory Invented by Talking About Beautiful Women - It is Used with Anything that is Dependent on Subjective Reasoning . . . . . . . . . . . . . . . 19

2.4 Fuzzy Theory Met with Severe Criticism . . . . . . . . . . 20

2.5 My Personal History - Getting Involved in Fuzzy Theory . 22

2.6 On Prof. Zadeh - The Father of Fuzzy Theory . . . . . . . 23 
3 Fuzzy Theory $\quad 25$

3.1 How to Define "Middle Age" . . . . . . . . . . . . 25

3.2 What is Fuzzy Theory? . . . . . . . . . . . . . . . 27

3.3 Notation of Fuzzy Theory . . . . . . . . . . . . . . . . 29

3.4 Representation of Subjectivity . . . . . . . . . . . . . . . 30

3.5 Operations in Fuzzy Theory . . . . . . . . . . . . . . . . 31

3.6 Concept of Speed and Fuzzy Theory . . . . . . . . . . . . 34

3.7 Consistency of Fuzzy Sets . . . . . . . . . . . . . . . . . 38

3.8 How to Think in Fuzzy Theory . . . . . . . . . . . . . 40

3.9 Difference Between Fuzzy Theory and Probability Theory . 42

3.10 What is Possibility Theory . . . . . . . . . . . . 43

3.11 Quantifying Uncertainty . . . . . . . . . . . . . . . 44

4 Applications of Fuzzy Theory $\quad 45$

4.1 Uncertainty not Accepted in Inference Based on

Binary Logic . . . . . . . . . . . . . . . . . . . . . 45

4.2 Daily Inference . . . . . . . . . . . . . . . . . . . . . . . . . . . . . . . .

4.3 Fuzzy Inference . . . . . . . . . . . . . . . . . . 47

4.4 Formalization of Fuzzy Inference . . . . . . . . . . . . 48

4.5 Artificial Intelligence and Uncertainty . . . . . . . . . . 51

4.6 How to Make Computers Thinks . . . . . . . . . . . . . . 52

4.7 Expert System - The Frontier of Artificial Intelligence . . 53

4.8 Fuzzy Expert Systems . . . . . . . . . . . . . . . . . . 54

4.9 Using the Fuzzy Expert System to Drive a Car . . . . . . . 55

4.10 The First Successful Example - Fuzzy Control . . . . . . . 60

4.11 The Principle of Fuzzy Control . . . . . . . . . . . . . . 63

4.12 Design Characteristics of Fuzzy Control . . . . . . . . . 66

4.13 Fault Tolerance Characteristic of Fuzzy Control . . . . . . . 68

4.14 Real Example of Fuzzy Control . . . . . . . . . . . . . . . . 69

4.15 Application in Social Science - Academic Uncertainty . . . 70

4.16 Evaluation of the Risk of Smoking . . . . . . . . . . 72

4.17 Fuzzy Survey . . . . . . . . . . . . . . . . . . 73

4.18 Fuzzy Similarity . . . . . . . . . . . . . . . 76

4.19 Difficulty with Conventional Data Bases . . . . . . . . . 78

4.20 Fuzzy Database . . . . . . . . . . . . . . . . . . . 81

4.21 Real Applications . . . . . . . . . . . . . . . . . . 83

5 Fuzzy Computers $\quad 85$

5.1 Demonstration of a Fuzzy Computer . . . . . . . . . . 85

5.2 Development Work on the Fuzzy Computer . . . . . . . . 87

5.3 Control Target of the Demonstration . . . . . . . . . 88 
5.4 Structure of a Fuzzy Computer . . . . . . . . . . . . . . . 90

5.5 Dream of a Fuzzy Computer . . . . . . . . . . . . . 91

6 Usefulness of Uncertainty $\quad 95$

6.1 Importance of Uncertainties . . . . . . . . . . . . . . . . . . 95

6.2 Use of Uncertainty . . . . . . . . . . . . . . . . . . . . . 97

6.3 Uncertainty and Organizations . . . . . . . . . . . . . 98

6.4 Uncertainty and Politicians . . . . . . . . . . . . . . . 100

6.5 Advantages of Fuzzy Theory . . . . . . . . . . . . . . . . . 101

6.6 Frequent Questions about Fuzzy Theory . . . . . . . . . . 103

6.7 Conclusions . . . . . . . . . . . . . . . . . . . . 104 


\section{List of Figures}

3.1 Definition of Middle Age in Conventional Sets . . . . . . 26

3.2 Definition of Middle Age in Fuzzy Sets . . . . . . . . . 28

3.3 Operations $A$ and $B, A$ or $B$, not $A \ldots \ldots . \ldots 34$

3.4 Fuzzy Sets "Safe Speed" . . . . . . . . . . . . . . 35

3.5 Fuzzy Set $B 1$ for Disease $a 1 \ldots \ldots \ldots$. . . . . . 38

3.6 Fuzzy Set $A 2$ for Disease $b 2 \ldots \ldots \ldots$

3.7 Fuzzy Set "Symptom" $B^{\prime} \ldots \ldots \ldots$

3.8 Fuzzy Set "Disease" for $B^{\prime} \ldots \ldots \ldots$

3.9 Degrees of Truth . . . . . . . . . . . . . . . 41

4.1 Steering the $\mathrm{Car} \ldots \ldots \ldots \ldots$

4.2 Membership Function "Angle of the Car" . . . . . . 57

4.3 Membership Function "Movement of the Steering Wheel" 58

4.4 Output with $x=5 \ldots \ldots \ldots \ldots$

4.5 Outputs with Various Angles $x \ldots \ldots \ldots 61$

4.6 "The car is veering slightly right" . . . . . . . . . . 62

4.7 Overview of Fuzzy Control . . . . . . . . . . . . . . . 64

4.8 Example . . . . . . . . . . . . . . . . . . . 65

4.9 Final Output . . . . . . . . . . . . . . . . . 66

4.10 Crisp Partition . . . . . . . . . . . . . . 67

4.11 Fuzzy Partition . . . . . . . . . . . . . . . . . 68

4.12 Fuzzy Sets with Regards to Smoking . . . . . . . . . . . 74

4.13 Fuzzy Graph . . . . . . . . . . . . . . . . . . . . . . . 77

4.14 Fuzzy Graph . . . . . . . . . . . . . . . . . . . 78

4.15 Basic Data . . . . . . . . . . . . . . . . . 80

4.16 Fuzzy Database . . . . . . . . . . . . . . . . . . 81

4.17 Interpretation Data . . . . . . . . . . . . . . . 82

4.18 Sample Answer to Query . . . . . . . . . . . . . 82

4.19 Fuzzy Decision ... . . . . . . . . . . . . . . 84

5.1 Prof. Yamakawa's Demonstration . . . . . . . . . . . 89 
5.2 Fuzzy Sets used by the Demonstration . . . . . . . . . 90

6.1 Face Chart . . . . . . . . . . . . . . . 97 


\section{List of Tables}

3.1 Membership Function . . . . . . . . . . . . . . . 29

3.2 Dice Numbers . . . . . . . . . . . . . . . . . . . . 32

3.3 Logical Operation with Dice Numbers . . . . . . . 33

3.4 Relationship Between Diseases and Symptoms . . . . . . . 35

3.5 Fuzzy Relation $R$ Between Diseases and Symptoms . $\quad 37$

3.6 Max-min Calculation . . . . . . . . . . . . . . 37

4.1 Fuzzy Relations $R 1, R 2, R 3 \ldots \ldots \ldots$

4.2 Subjective Survey . . . . . . . . . . . . . . 76

4.3 Fuzzy Relation $\ldots \ldots \ldots \ldots 76$

4.4 Similarity Relation . . . . . . 77

5.1 Fuzzy Rules for Computation of $\omega \ldots$. . . . . . . . 90 